\title{
O ESTÁGIO CURRICULAR SUPERVISIONADO DE OBSERVAÇÃO: TECENDO REFLEXÕES E REFLETINDO SOBRE ESSE ESPAÇO DE FORMAÇÃO
}

\section{ARTIGO ORIGINAL}

ROCHA, Ermita do Amaral ${ }^{1}$

SILVA, Américo Junior Nunes da ${ }^{2}$

ROCHA, Ermita do Amaral. SILVA, Américo Junior Nunes da. O estágio curricular supervisionado de observação: Tecendo reflexões e refletindo sobre esse espaço de formação. Revista Científica Multidisciplinar Núcleo do Conhecimento. Ano 05, Ed. 06, Vol. 07, pp. 61-71. Junho de 2020. ISSN: 2448-0959, Link de acesso: https://www.nucleodoconhecimento.com.br/educacao/estagio-curricular

\section{RESUMO}

Esse relato objetiva apresentar e refletir sobre uma experiência de observação ocorrida ao longo do Estágio Curricular Supervisionado I, durante o segundo semestre de 2019, em uma turma de $8^{\circ}$ ano do Ensino Fundamental em uma escola municipal da cidade de Senhor do Bonfim - Bahia. O texto apresenta reflexões sobre o papel do estágio na formação do professor de Matemática e das experiências vivenciadas nesse período de formação, refletindo no quanto essas atividades foram importantes para a constituição da identidade docente do estagiário. Respaldamos teoricamente

\footnotetext{
${ }^{1}$ Estudante do Curso de Licenciatura em Matemática da Universidade do Estado da Bahia (UNEB).

2 Doutor em Educação pela Universidade Federal de São Carlos (UFSCar), Mestre em Educação pela Universidade de Brasília (UnB), Especialista em Psicopedagogia Institucional e Clínica pela Faculdade Regional de Filosofia, Ciências e Letras de Candeias (IESCFAC), Especialista em Educação Matemática e Licenciado em Matemática pelo Centro de Ensino Superior do Vale do São Francisco (CESVASF).
} 
as discussões a partir de produções de Pimenta (1999) e Pimenta e Lima (2004), para as questões de estágio e com D’Ambrosio (1993) e Silva (2014) para a formação do professor de Matemática. Por fim, apesar das constantes dificuldades enfrentadas na realização do estágio, entendemos terem sido necessárias para que pudéssemos entender a complexidade que é o processo de formação, ensino e aprendizagem de Matemática.

Palavras-Chave: Estágio, formação inicial, matemática, reflexão, ensino.

\section{INTRODUÇÃO}

O Estágio Curricular Supervisionado é um espaço presente na formação de qualquer profissional, onde o universitário envolve-se, como destacam Suzart e Silva (2020, no prelo), no local de futura atuação profissional com o propósito de realizar reflexões sobre seu processo de formação e, com isso, constituir e fortalecer a sua identidade profissional. É nesse espaço, também, que o estudante construirá conhecimentos e habilidades presentes em seu campo de futura atuação e que só é possível nesse movimento de "viver", na prática, seu campo de trabalho.

O Estágio Curricular Supervisionado (ECS) é obrigatório nos cursos de graduação e faz parte da Licenciatura em Matemática da Universidade do Estado da Bahia (UNEB) do Campus VII, Senhor do Bonfim - BA, sendo assegurado na instituição com a Resolução CONSEPE № 2.016/2019. O fluxograma do curso, presente em seu Projeto Pedagógico de Curso, Bahia (2011), apresenta oito semestres, totalizando quatro anos. $O$ estágio, presente nos últimos quatro semestres, possui uma carga horária total de 405 horas. Os ECS I e II são realizados em turmas dos anos finais do Ensino Fundamental e o ECS III e IV no Ensino Médio. O primeiro estágio em cada modalidade de ensino destina-se a observação e o seguinte a docência.

O Estágio Curricular Supervisionado I, presente no 5ำ semestre do curso, foi dividido em $30 \mathrm{~h}$ de atividades para supervisão, estudos, discussões e orientações na Universidade e $45 \mathrm{~h}$ para as atividades a serem desenvolvidas na unidade escolar. Dentro da escola, foram 16h para o primeiro contato: a) leitura do Projeto Político 
Pedagógico (PPP); b) conversa com a professora supervisora[3] sobre questões ligadas a sala de aula e aplicação de questionário construído no espaço da Universidade e; c) participação nas Atividades Complementares (AC). Todas essas atividades foram necessárias para conhecer esse espaço enquanto ambiente de formação e pesquisa, como destaca Pimenta (1999), além de ser importante para a familiarização do futuro professor e interação com os documentos que regem a instituição e com as atividades da prática docente (PIMENTA, 2012). As demais $29 \mathrm{~h}$ foram destinadas para a observação, em sala de aula, de uma turma de Matemática do $8^{\circ}$ ano do Ensino Fundamental.

Esse relato objetiva apresentar e refletir sobre a experiência vivenciada no ECS I, ocorridos em uma turma do 8 $\stackrel{-}{-}$ ano do Ensino Fundamental, em uma escola pública da cidade de Senhor do Bonfim - Bahia, durante o segundo semestre do ano de 2019. O texto apresenta, a priori, uma reflexão sobre o papel do estágio na formação do professor de Matemática e como as experiências vivenciadas nesse período de estágio foram importantes para a formação e constituição da identidade docente do estagiário.

\section{ESTÁGIO E A FORMAÇÃO DOCENTE}

O estágio é um conjunto de atividades de formação, realizadas sob a supervisão de docentes da instituição formadora, e acompanhado por profissionais, em que o estudante experimenta situações de efetivo exercício profissional. O estágio supervisionado tem o objetivo de consolidar e articular as competências desenvolvidas ao longo do curso por meio das demais atividades formativas, de caráter teórico ou prático. (BRASIL, 2005, p. 3).

Escolhemos esse excerto, para dar início a essa seção, por considerá-lo oportuno para as discussões aqui empreendidas, sobretudo, no que tange a necessidade de definir o termo "estágio", uma vez que se trata do objeto de discussão desse artigo. $\mathrm{O}$ estágio é, corroborando ao destacado, um importante momento na formação docente onde o acadêmico vivencia, enquanto futuro professor, o ambiente da escola, seus 
profissionais, alunos, ou seja, é o espaço que aproxima o graduando do ambiente que futuramente atuará. Vale destacar que esse espaço é importante, como assevera Pimenta (1999) e Pimenta (2012), sobretudo, para ressignificar concepções, que esses futuros professores apresentem, uma vez que enquanto aluno tiveram vivências anteriores diversas e que, muitas vezes, apresentam-se equivocadas.

Pimenta e Lima (2004), por exemplo, traçam uma discussão com o objetivo de desconstruir a ideia de que o estágio possui um papel, na formação do professor, de "a hora da prática". Segundo as autoras importa percebê-lo enquanto espaço permanente de articulação e vivência entre teoria e prática. Essa fragmentação, presente em cursos de formação de professores, fragiliza, muitas vezes, a formação do professor por, ao longo do curso, desarticular as ações desenvolvidas na licenciatura com as diferentes realidades educacionais. As autoras ainda evidenciam que espaços que discutem essas questões em muitos cursos, como é o caso da prática como componente curricular, também garantido legalmente, como destaca o Parecer CNE/CES № 15/2005, são desvalorizados. Pensando na necessária articulação teoria e prática, Suzart e Silva (2020, p. 4, no prelo) evidenciam que

[...] entendemos o ECS como um movimento que permite a transposição da teoria para uma prática específica, possibilitando um ressignificar "teórico-prático-teórico" ou "prático-teórico-prático", na medida em que aproxima os futuros docentes das vivências da profissão docente; essa aproximação produz reflexões acerca da realidade escolar vivenciada. Essa ressignificação mencionada anteriormente, ainda pensando na indissociabilidade que há entre teoria e prática, poderia ser mais bem explicitada. Retomando o apresentado, diríamos que pelo movimento "teórico-prático-teórico" é que é possível que a teoria, enquanto ponto de partida, oriente a prática e que esta, por sua vez, retorne sobre as questões teóricas, iluminando-as. Paralelamente, o movimento "práticoteórico-prático" permite que o inverso ao apresentado antes aconteça: que a prática oriente/ressignifique a teoria que retoma, por sua vez, as questões práticas. Esses dois movimentos pendulares dialogam. 
Nessa direção, de acordo com Pimenta e Lima (2004), importa-nos apresentar a concepção do estágio, também, enquanto campo de pesquisa. Isso nos permite entendê-lo como espaço do tornar-se pesquisador de sua própria prática, ou seja, o professor como profissional reflexivo e pesquisador da prática docente dentro dos espaços escolares. Essa visão segue defendida por Pimenta (1999, p. 18), ao acrescentar que o estágio corrobora a construção da identidade profissional, em que

Espera-se, pois, que mobilize os conhecimentos da teoria da educação e da didática necessários à compreensão do ensino como realidade social, e que desenvolva neles a capacidade de investigar a própria atividade para, a partir dela, construírem e transformarem os seus saberes-fazeres docentes, num processo contínuo de construção de suas identidades como professores.

Portanto, o estágio na formação docente é um dos espaços para a construção da identidade do profissional e que, por vezes, faz-se necessário a reformulação e revisão da sua compreensão social. Ainda de acordo com a autora, o primeiro passo "que se propõe a mediar o processo de construção de identidade dos futuros professores" (PIMENTA, 1999, p. 19) é mobilizar os saberes da experiência, ou seja, utilizar e ressignificar suas experiências como aluno, com outros professores nesse movimento de passagem do ser aluno para o ser professor. Além disso, os diferentes conhecimentos necessários à docência, como evidência Shulman (2005), são fundamentais para a construção da identidade docente.

Nesse sentido, portanto, o espaço escolar constitui-se enquanto ambiente importante para esse processo de formação e, por permitir que esse perfil de professor que pesquisa(rá) a própria prática se fortaleça. Necessário considerar que, o futuro professor de Matemática, ao longo do curso de licenciatura, precisará observar os elementos que estão presentes no ensino da matemática: o professor, o aluno, o saber matemático e o meio/contexto (SANTOS, 2002). O licenciando compreenderá, partindo daí, as relações existentes entre esses quatro elementos, e verá que eles são indissociáveis, complementares e igualmente importantes (VIEIRA e SILVA, 2020, no prelo). Por isso, na próxima seção, apresentaremos as nossas percepções acerca 
da escola parceira e campo de estágio, por entendê-la importante para esse movimento de se constituir docente que ensina Matemática.

\section{CONHECENDO A ESCOLA}

O primeiro contato com a escola, para a realização do estágio, é importante, por ser um momento em que o estagiário idealiza o estar nesse espaço e sua experiência durante esse período, projetando a sua futura atuação. Nesse sentido, ao chegar à escola e recebidos pela diretora, solicitamos o Projeto Político Pedagógico (PPP) para conhecer os objetivos, metas e o que pretendem, tanto no âmbito pedagógico como administrativo. Diante do solicitado fomos informados que o PPP estava desatualizado e em processo de correção. O documento que nos foi entregue datava do ano de 2016. Como destacam Suzart e Silva (2020, p. 03, no prelo)

Esse movimento de conhecer o PPP da escola é uma atividade inicial do estágio. Trata-se de um documento que nos permite uma aproximação com os pressupostos teórico e metodológico que embasam o fazer pedagógico da escola. Lê-lo, em um primeiro momento, nos permitiu, ao adentrar de fato nos espaços escolares, como na sala de aula de matemática, perceber como o que se pensou na construção do currículo reverbera nas práticas cotidianas.

Inaugurada em Maio de 2000, a escola contava com oito salas de aula e foi municipalizada em 2013. Até hoje possui a mesma planta. O nome da escola foi em homenagem a uma professora do município, que além da escola, foi diretora fundadora de outras instituições na cidade, como por exemplo, o Colégio Estadual de Senhor do Bonfim, e a Faculdade de Educação do Estado da Bahia (FESB). A escola atende alunos dos anos finais do ensino fundamental ( $6^{\circ}$ ao $9^{\circ}$ ano), nos turnos matutino e vespertino, com uma diretora e dois vice-diretores.

Conhecemos a estrutura da escola, circulando e conversando com a professora supervisora. Percebemos que não há laboratório de ensino de Matemática e os poucos materiais que possui são provenientes de construções em sala de aula pelos 
próprios alunos, como para a Feira de Matemática que acontece todo ano por exemplo. Nessa direção, a professora supervisora evidencia[4] a falta de recursos disponibilizados e materiais didáticos como um fator que interfere o bom andamento das aulas.

Segundo o PPP e a professora supervisora, a escola possui biblioteca composta por livros didáticos escolhidos para serem utilizados nas aulas, os quais são alocados em duas prateleiras na sala dos professores. A escola possui uma sala de vídeo climatizada, uma quadra poliesportiva descoberta, grande extensão do pátio aberto e coberto. As salas não possuem ventiladores, a porta sem trinco e nem maçaneta, as paredes e os murais riscados com nomes de alunos e frases com "palavrões". Embora tenha, em seu espaço, um laboratório de informática, o mesmo pertence a uma instituição privada que oferece cursos de graduação à distância, não podendo ser usado pela comunidade escolar. A sala dos professores possui alguns pequenos armários, um banheiro e um ventilador móvel.

Nesse contexto, pensando na importância que essa estrutura física tem para a construção de um espaço de formação apropriado, Coelho e Orzechowski (2011), traz a reflexão sobre a função social que a escola pública possui, fruto de longas lutas ainda hoje presentes. Segundo as autoras, a escola existe por uma necessidade humana, ou seja, a educação necessária para formar cidadãos críticos e reflexivos, capazes de transformar a sociedade. Portanto, o professor precisa conhecer essa função social para auxiliar o aluno em seu desenvolvimento educacional e no tornarse "ser-humano", como também destacam as autoras.

Os planos de curso da escola estavam anexos ao PPP e, segundo a professora supervisora, é construído "com profissionais, professores e coordenadores da unidade escolar". O planejamento das aulas é realizado semanalmente, pelos docentes e coordenadora, e esse momento é conhecido como Atividades Complementares (AC). Para ela é nesse momento de atividades que é "abordado os conteúdos a serem dados". A professora não menciona se é feito algum outro momento de reflexão e diálogo sobre a escola e a aprendizagem dos alunos, o que deveria, pela nossa percepção, ser pauta principal desses encontros. 
Acerca disso, Silva et al (2014) refletem sobre a importância do planejamento nas unidades escolares, em especial na prática docente do professor de Matemática. Indubitavelmente, $\mathrm{o}$ ato de planejar é essencial para que o processo de ensino e aprendizagem tenha um objetivo definido pelo professor e que não aconteça apenas para atender uma demanda burocrática da instituição.

\section{A PROFESSORA SUPERVISORA E OS ALUNOS DA TURMA}

Para obtermos informações da professora, além das frequentes conversas durante o período do estágio, foi construído um questionário com perguntas envolvendo desde a formação e ato de planejar até as práticas desenvolvidas em suas aulas e as impressões sobre os estudantes e as suas dificuldades. Para traçar os perfis dos discentes utilizamos principalmente a observação e diálogos com a professora.

A professora da turma, formada recentemente em Licenciatura em Matemática, atua em duas escolas e com reforço escolar há quase três anos. Utiliza os livros didáticos para seguir a ordem dos conteúdos e faz seus planos de aula fora do planejamento realizado semanalmente na escola, baseando, segundo ela, na Base Nacional Comum Curricular (BNCC) e nos Parâmetros Curriculares Nacionais (PCN).

Vale destacar que a professora atua na escola observada a pouco mais de três meses. Para ela, a Matemática é importante "pois aplicamos no nosso cotidiano mesmo sem saber". Essa concepção de Matemática vai ao encontro do que destaca D’Ambrósio (1993) ao discutir sobre a responsabilidade do docente em mostrar a Matemática útil para seus alunos. É importante ressaltar que, em suas aulas, a professora tenta explicar e exemplificar exatamente com situações do dia a dia ou objetos contidos em sala de aula. D’Ambrosio (1993, p.37) ressalta que "o ambiente necessário para a construção de uma visão de Matemática conforme proposta pelos construtivistas caracteriza-se por um ambiente em que os alunos propõem, exploram e investigam problemas matemáticos".

De acordo com a caderneta da turma foram matriculados, no ano letivo de 2019, dezessete alunos, em sua maioria meninos, porém com baixa frequência. As aulas 
são em muitas das vezes expositivas com atividades após a explicação. Em alguns momentos a professora faz dinâmica com papel ou apresentações com cartolina. Vale ressaltar que alguns estudantes trabalham no turno oposto. Os alunos conversam durante a aula, brincam ao longo das explicações da professora, saem de sala [outros nem entram ou ficam na quadra ou pátio]. O portão da escola quase sempre fica aberto e muitos alunos vão embora após a primeira aula, como aconteceu em muitas aulas observadas.

A docente ao ser questionada sobre as dificuldades de aprendizagem da turma, responde que "os alunos se evadem da aula e diz não gostar de Matemática". Esse desestímulo dos alunos resulta na desmotivação da professora, como sinalizado por ela. Além disso, menciona a falta de material pedagógico como um aspecto que contribui para as dificuldades com o ensino. Nessa direção, como evidencia Bisognin, (2015, p.15)

Verifica-se que o retrabalho dos professores, em sala de aula, no sentido de construir constantemente uma base de conhecimento, está relacionado a fatores externos, que fogem ao alcance do docente, mas que infelizmente impactam diretamente no resultado de seu trabalho com os alunos.

Portanto, existem diversos fatores externos que podem contribuir diretamente com as dificuldades apresentadas pelos alunos. Consequentemente, ao questionada sobre 0 nível de satisfação com a profissão, a professora responde que "infelizmente caótica, igualmente aos médicos que atendem pelo SUS". Esse desabafo mostra a situação emocional de muitos professores da escola pública, frustrados com o desânimo dos alunos e com as péssimas condições de trabalho.

\section{OBSERVAÇÕES DAS ATIVIDADES}

As observações foram realizadas no período de outubro a dezembro de 2019. A professora, durante esse período, trabalhou com produtos notáveis, triângulos e semelhança de triângulos, utilizando diversos métodos de avaliação, como por 
exemplo, o visto em atividades, participação em construções em sala de aula, atividade escrita e prova ao final da unidade.

De acordo com o questionário aplicado, a escola obriga existir duas avaliações (teste e prova) e somatória de atividades. Costa e Albuquerque (2015) denomina esse processo avaliativo como "plano formal", que possui como objetivo examinar o aluno. A docente tenta mesclar os métodos avaliativos, buscando analisar a desenvoltura dos alunos na realização de atividades diferentes das escritas. Inicialmente os alunos não ficaram com vergonha por ter alguém os observando, eles conversavam conosco, perguntando o que estávamos fazendo na sala. A professora escrevia o conteúdo no quadro e esperava os alunos escreverem. Mesmo assim muitos nem abriam o caderno ou ficavam conversando ou utilizando o celular. No período dos jogos estudantis, onde são realizados torneios de futebol entre as escolas do município, os alunos não iam para a escola. Vários dias a professora ao chegar à sala tinha apenas três alunos, isso foi frequente em alguns dias de observação.

A turma demonstrava gostar da professora, havendo uma liberdade para conversarem de outros assuntos durante as aulas. Por algum motivo burocrático a professora concursada que dava aula de matemática nessa turma foi afastada no início do ano e desde então houve uma alternância de profissionais, até a permanência da atual docente. É sabido que essa constante mudança de professora e consequentemente de diferentes metodologias vivenciadas por elas, afeta o desenvolvimento da turma em relação as aprendizagem matemáticas. Com isso, frequentemente, os alunos se queixavam dessas mudanças de professora e relatava o quanto isso afetou no processo de aprendizagem.

Foi notória a dificuldade dos alunos com a Matemática. Frequentemente é mencionado por eles que não gostam da disciplina e nem conseguem aprender. Bisognin (2015, p.12) destaca as possíveis consequências dessa concepção negativa dos alunos, pois "desse modo, a Matemática ao se configurar para os alunos como algo de difícil compreensão, sendo de pouca utilidade prática, produz representações e sentimentos que vão influenciar no desenvolvimento da aprendizagem." Ou seja, o sentimento de autoconfiança do aluno no processo de ensino e aprendizagem é 
fundamental para que ele consiga construir uma boa relação com a disciplina. Essa mesma discussão é apresentada no trabalho de Lima; Kegler e Broch (2019), o qual também é um relato da experiência desenvolvida durante um estágio de observação, como o nosso. De acordo com as autoras apesar das dificuldades, os alunos falam que gostam das aulas de Matemática, diferentemente das falas em sala de aula da turma observada.

Uma dificuldade enfrentada pela professora na realização de aulas atrativas para os alunos é a falta de material pedagógico disponibilizado para escola ou até a falta de material para construções em sala de aula. A direção não disponibiliza pilotos nem apagador, a aquisição é de responsabilidade de cada docente, como também material para dinâmicas, apresentações, construções durante as aulas.

\section{CONSIDERAÇÕES FINAIS}

O estágio é o momento, para muitos, do primeiro contato do futuro professor com o ambiente que irá atuar, onde se aproxima da realidade escolar, sua estrutura, direitos e deveres, seus funcionários e alunos. Entretanto, essa imersão no espaço escolar não deveria acontecer somente na reta final do curso, mas acaba sendo na maioria das propostas curriculares. Além disso, esse contato tardio com a escola influencia a decisão de seguir nessa área profissional, conhecendo suas alegrias e angústias durante o processo de ensino e aprendizagem.

O estágio de observação oportuniza ao graduando analisar a prática de outro profissional e as diferentes interações que acontecem na escola, com um olhar de pesquisador, possibilitando (re)pensar seu papel, quando do assumir a docência, havendo, durante as aulas, discussões e reflexões que estabelecem constantemente relações entre a teoria e a prática.

Por fim, apesar das constantes dificuldades enfrentadas na realização do estágio, entendemos que foram necessárias para que pudéssemos entender a complexidade que é o processo de formação e ensino e aprendizagem de Matemática. Foi importante essa realidade para construção da identidade profissional, para análise dos 
rumos que a nossa atual juventude está tomando e para a reflexão do ato de ensinar e inovar a Matemática, transformando o bloqueio existente no meio discente em um processo lúdico e transformador.

\section{REFERÊNCIAS}

BAHIA. Projeto Pedagógico do Curso de Licenciatura em Matemática da Universidade do Estado da Bahia, campus VII. Senhor do Bonfim: Universidade do Estado da Bahia, 2011.

BAHIA. Resolução CONSEPE № 2016/2019. Regulamento Geral de Estágio da Universidade do Estado da Bahia. Salvador: Universidade do Estado da Bahia, 2019.

BRASIL. Parecer CNE/CES no 15, de 02 de fevereiro de 2005. Solicitação de esclarecimento sobre as Resoluções CNE/CP nos 1/2002, que institui Diretrizes Curriculares Nacionais para a Formação de Professores da Educação Básica, em nível superior, curso de licenciatura, de graduação plena, e 2/2002, que institui a duração e a carga horária dos cursos de licenciatura, de graduação plena, de Formação de Professores da Educação Básica, em nível superior. Brasília, DF, 2005.

BISOGNIN, Bibiane. Valessa. Moreira. Um olhar dos professores sobre as dificuldades de aprendizagem em matemática nos anos finais do ensino fundamental. Trabalho de Conclusão de Curso de Licenciatura em Matemática. Universidade Federal de Santa Maria - Rio Grande do Sul. 2015.

COELHO, Nara.; ORZECHOWSKI, Suzete. Terezinha. A função social da escola pública e suas interfaces. IN: I Seminário Internacional de Representações Sociais, Subjetividade e Educação - SIRSSE. Pontífice Universidade Católica do Paraná, 7 10 nov 2011.

Disponível

em: <http://educere.bruc.com.br/CD2011/pdf/6443_3792.pdf >. Acesso em: 12 de dez de 2019

COSTA, Andreia. Alves.; ALBUQUERQUE, Leila. Cunha de. Avaliação da aprendizagem matemática na perspectiva dos processos avaliativos utilizados por 
professores do ensino fundamental anos finais. Periódico Científico Projeção e Docência. v.6, n.2, 2015. ISSN: 2178-6275

D'AMBRÓSIO, Beatriz. Formação de professores de matemática para o século XXI: O grande desafio. Pró - Posições, Campinas, n. 1 (10) p. 35-40, mar.1993.

LIMA, Kadja. Silveira.; KEGLER, Natália. Alessandra.; BROCH, Siomara. Cristina. Vivências de Estágio de Observação no Ensino Fundamental. Educação Matemática em Revista, Brasília, v. 24, n. 62, p. 166-177, abr./jun. 2019

PIMENTA, Selma Garrido. Formação de professores: identidade e saberes da docência. In: PIMENTA, Selma Garrido. (Org). Saberes pedagógicos e atividade docente. São Paulo: Cortez Editora, 1999.

PIMENTA, Selma Garrido; LIMA, Maria Socorro Lucena. Estágio e Docência. São Paulo: Cortez, 2004. (Coleção docência em formação. Séries saberes pedagógicos).

PIMENTA, S. G. O Estágio na Formação de Professores - Unidade Teoria e Prática? 11… ed. São Paulo: Cortez, 2012.

SANTOS, V. M. O Desafio de Tornar-se Professor de Matemática. In: NUANCES: estudos sobre educação. ano VIII, n. 08. set. 2002. Disponível em: https://revista.fct.unesp.br/. Acessado em: 21 abr. 2020.

SHULMAN, L. S. Conocimiento y enseñanza: fundamentos de la nueva reforma. Profesorado. Revista de Currículum y formación del profesorado, v. 9, n. 2, p. 1-30, 2005. Disponível em: <http://www.ugr.es/ recfpro/Rev92.html>. Acesso em: $15 / 05 / 2020$.

SILVA, Américo. Junior. Nunes da.; SOUZA, Ivanete. dos Santos de.; BARROS, Simone. Santos.; ALMEIDA, Gefferson. Dias Silva. A formação do professor de Matemática em Questão: Reflexões para um ensino com significado. Jundiaí, Paco Editorial: 2014. 
SUZART, L. A. SILVA, A. J. N. S. O Estágio Supervisionado e o constituir-se professor de Matemática: "ser ou não ser professor?". Educação Básica Revista, São Paulo, v. 6 , n. 1, 2020. No prelo.

VIEIRA, E. S. SILVA, A. J. N. S. Dominó Fracionário: uso do material didático para o ensino de frações. Revista Mundo Livre, Rio de Janeiro, v. 6, n. 1, 2020. No prelo.

\section{APÊNDICE - REFERÊNCIAS DE NOTA DE RODAPÉ}

3. A professora supervisora é a professora da escola que aceita o estagiário para realizar as atividades de estágio;

4. Para conhecer mais da professora supervisora e das concepções que apresenta quanto a sua formação e ao ensino de matemática, foi entregue um questionário, construído no espaço da universidade;

Enviado: Maio, 2020.

Aprovado: Junho, 2020. 